\title{
Assignment of sigma factors of RNA polymerase to promoters in Corynebacterium glutamicum
}

\author{
Hana Dostálová1, Jiří Holátko', Tobias Busche², Lenka Rucká1, Andrey Rapoport ', Petr Halada', Jan Nešvera',
} Jörn Kalinowski ${ }^{2}$ and Miroslav Pátek ${ }^{1 *}$ (D)

\begin{abstract}
Corynebacterium glutamicum is an important industrial producer of various amino acids and other metabolites. The $C$. glutamicum genome encodes seven sigma subunits (factors) of RNA polymerase: the primary sigma factor SigA $\left(\sigma^{A}\right)$, the primary-like $\sigma^{B}$ and five alternative sigma factors $\left(\sigma^{C}, \sigma^{D}, \sigma^{E}, \sigma^{H}\right.$ and $\left.\sigma^{M}\right)$. We have developed in vitro and in vivo methods to assign particular sigma factors to individual promoters of different classes. In vitro transcription assays and measurements of promoter activity using the overexpression of a single sigma factor gene and the transcriptional fusion of the promoter to the gfpuv reporter gene enabled us to reliably define the sigma factor dependency of promoters. To document the strengths of these methods, we tested examples of respective promoters for each $C$. glutamicum sigma factor. Promoters of the rshA (anti-sigma for $\sigma^{H}$ ) and $\operatorname{tr} x B 1$ (thioredoxin) genes were found to be $\sigma^{\mathrm{H}}$-dependent, whereas the promoter of the $\operatorname{sig} B$ gene (sigma factor $\sigma^{\mathrm{B}}$ ) was $\sigma^{\mathrm{E}}$ - and $\sigma^{\mathrm{H}}$-dependent. It was confirmed that the promoter of the cg2556 gene (iron-regulated membrane protein) is $\sigma^{C}$-dependent as suggested recently by other authors. The promoter of $\mathrm{cmt}^{1}$ (trehalose corynemycolyl transferase) was found to be clearly $\sigma^{\mathrm{D}}$-dependent. No $\sigma^{\mathrm{M}}$-dependent promoter was identified. The typical housekeeping promoter P2sigA (sigma factor $\sigma^{\mathrm{A}}$ ) was proven to be $\sigma^{A}$-dependent but also recognized by $\sigma^{B}$. Similarly, the promoter of $f b a$ (fructose-1,6-bisphosphate aldolase) was confirmed to be $\sigma^{B}$-dependent but also functional with $\sigma^{A}$. The study provided demonstrations of the broad applicability of the developed methods and produced original data on the analyzed promoters.
\end{abstract}

Keywords: Corynebacterium glutamicum, Promoter, Sigma factor, In vitro transcription, RNA polymerase

\section{Introduction}

The multisubunit RNA polymerase (RNAP) holoenzyme in bacteria consists of core enzyme $\left(2 \alpha, \beta, \beta^{\prime}\right.$ and $\omega$ subunits) and a dissociable $\sigma$ subunit ( $\sigma$ factor) that recognizes specific promoter sequences. Sigma factors are thus key regulatory elements that control different classes of promoters and activate expression of the respective groups of genes (regulons or sigmulons). Bacterial cells adapt in this way to changes in nutritional and environmental conditions. Bacteria typically possess a primary $\sigma$ factor that is responsible for the transcription of housekeeping

\footnotetext{
*Correspondence: patek@biomed.cas.cz

${ }^{1}$ Institute of Microbiology of the CAS, v. v. i., Vídeňská 1083, 14220 Prague 4, Czech Republic

Full list of author information is available at the end of the article
}

genes and a variable number of alternative $\sigma$ factors that enable the cell to cope with various environmental stimuli. Since the activities of the different holo-RNAPs and the respective promoters orchestrate the cell metabolism in complex responses to various nutrition, growth and stress conditions, engineering $\sigma$ factors has recently become a promising field in biotechnology and synthetic biology, particularly for the development of synthetic transcriptional control (Rhodius et al. 2013; Tripathi et al. 2014).

Corynebacterium glutamicum is a Gram-positive non-pathogenic soil bacterium used particularly for the industrial production of $\mathrm{L}$-amino acids. The existing large toolbox for the genetic and metabolic engineering of C. glutamicum (Nešvera and Pátek 2011) enabled 
the construction of C. glutamicum producers of amino acids, carboxylic acids, alcohols, amines, polymers and biofuels as well as the use of alternative carbon sources like organic acids, pentoses, glycerol, starch and cellulose (Becker and Wittmann 2012). The C. glutamicum genome encodes seven sigma subunits of RNAP: the primary sigma factor $\sigma^{\mathrm{A}}$, the alternative primary-like $\sigma^{\mathrm{B}}$ and five other alternative $\sigma$ factors with extracytoplasmic functions (ECF) $\left(\sigma^{\mathrm{C}}, \sigma^{\mathrm{D}}, \sigma^{\mathrm{E}}, \sigma^{\mathrm{H}}\right.$ and $\left.\sigma^{\mathrm{M}}\right)$ (for a review, see Pátek and Nešvera 2011).

Corynebacterium glutamicum $\sigma^{\mathrm{A}}$ is an essential primary $\sigma$ factor that directs the transcription of the majority of genes expressed during exponential growth which are termed "housekeeping" or "vegetative". The promoters are usually considered housekeeping ( $\sigma^{\mathrm{A}}$-dependent) if their -35 and -10 promoter sequences match the generally accepted consensus of housekeeping promoters. The consensus sequence of $\sigma^{\mathrm{A}}$-dependent promoters ( -35 ttgnca and -10 TAnnnT) was deduced from a large number of defined promoters (Pátek and Nešvera 2011; Pfeifer-Sancar et al. 2013) which are believed to be $\sigma^{\mathrm{A}}$-dependent.

$\sigma^{\mathrm{B}}$ is a non-essential primary-like $\sigma$ factor that is present in C. glutamicum cells in the highest levels at the transition and in the early stationary phase (Larisch et al. 2007). It is involved in responses to various stresses such as acid and heat stress and oxygen deprivation (Ehira et al. 2008; Halgasova et al. 2002). In addition to its involvement in stress-protective functions, $\sigma^{\mathrm{B}}$ drives the transcription of the genes active in glucose utilization during exponential growth (Ehira et al. 2008). $\sigma^{\mathrm{B}}$ can thus be considered to be a $\sigma$ factor for slow growth and general stress conditions and another $\sigma$ factor that recognizes some housekeeping promoters in the exponential growth phase. Only a few $\sigma^{\mathrm{B}}$-dependent promoters (13 in the review of Pátek and Nešvera 2011) have been localized and their key sequences were found to be essentially indistinguishable from the consensus sequences of $\sigma^{\mathrm{A}}$ dependent promoters.

$\sigma^{\mathrm{H}}$ is the most studied C. glutamicum ECF sigma factor, which controls a transcriptional regulatory network enabling the C. glutamicum cell to respond to temperature, oxidative and growth-phase induced stresses (Busche et al. 2012; Ehira et al. 2009; Toyoda and Inui 2016b; Toyoda et al. 2015). The consensus sequence $-35 \mathrm{~g} / \mathrm{tGGAAt}$ and $-10 \mathrm{t} / \mathrm{cGTTgaa}$ was defined (Busche et al. 2012; Ehira et al. 2009) based on the 45 proposed $\sigma^{\mathrm{H}}$-regulated promoters.

Corynebacterium glutamicum $\sigma^{\mathrm{E}}$ was found to be involved in heat and cell surface stress response (Park et al. 2008). We have recently shown that the promoters $\mathrm{P} 1$ clgR, P2dnaK and P2dnaJ2 are recognized by both $\sigma^{\mathrm{E}}$ and $\sigma^{\mathrm{H}}$ (Šilar et al. 2016). This indicates that there is a certain overlap in promoter recognition specificity for $\sigma^{\mathrm{H}}$ and $\sigma^{\mathrm{E}}$. The consensus sequence of $\sigma^{\mathrm{E}}$-specific promoters has not been determined yet.

The $\sigma^{\mathrm{C}}$ regulon that is induced in response to defects in aerobic respiration has been recently described (Toyoda and Inui 2016a). Eight $\sigma^{\mathrm{C}}$-specific promoters were found, and their consensus sequence was defined as -35 GGAAAC and - 10 CGACT.

A group of genes involved in oxidative stress response was found to be $\sigma^{\mathrm{M}}$-dependent (Nakunst et al. 2007). Some of these genes were found to be $\sigma^{\mathrm{H}}$-dependent in another study (Ehira et al. 2009). It therefore needs to be elucidated whether $\sigma^{\mathrm{H}}$ and $\sigma^{\mathrm{M}}$ are members of a regulatory cascade or if their recognition specificities overlap. No $\sigma^{\mathrm{D}}$-dependent genes and $\sigma^{\mathrm{D}}$-specific promoters have been described yet.

It was found that the overexpression of the C. glutamicum sigH gene resulted in enhanced riboflavin biosynthesis and its excretion to the medium (Taniguchi and Wendisch 2015; Toyoda et al. 2015). Further advances in the use of $\sigma$ factor manipulations are still hampered in $C$. glutamicum by limited knowledge of the mechanisms of $\sigma$ factor regulations, as well as by current lack of reliable methods for identifying the target promoters for various $\sigma$ factors.

Knowledge of the recognition specificity of $\sigma$ factors and assignment of $\sigma$ factors to particular promoters is necessary to modulate the effects of sigma factors on the production of specific metabolites. In addition to manipulating sigma factors, the construction of artificial promoters recognized by specific $\sigma$ factors is a promising strategy for modulating gene expression and improving the production of selected metabolites (Pátek et al. 2013). A self-inducible $\sigma^{\mathrm{B}}$-dependent $C$. glutamicum promoter has recently been developed which can be useful for the production of metabolites in the stationary growth phase (Kim et al. 2016).

Multiple promoters upstream of many bacterial genes pose another challenge to their classification. The genes have frequently two or more promoters, which can overlap. Two overlapping promoters can be controlled by different sigma factors. Moreover, some promoters are recognized by two or even more sigma factors. As a result, determining which regulon the gene belongs to may be difficult. Overlapping $\sigma$-factor binding sites were detected frequently in Escherichia coli: e.g. 38 genes were assigned to 4 different sigma factors and 2 genes were even assigned to 6 sigma factors (Cho et al. 2014).

In this study, we used an in vitro transcription system and in vivo methods (overexpression of sigma genes to drive transcription from the promoters transcriptionally fused to the gfpuv reporter, use of sig-deletion strains) to reliably determine which sigma factors control 
transcription driven by individual tested promoters in $C$. glutamicum. We analyzed both housekeeping $\sigma$ factors and ECF $\sigma$ factors involved in stress responses. Overexpression of the sig genes encoding ECF $\sigma$ factors usually results in the stronger expression of the $\sigma$ factor-specific genes, even in the absence of the respective stress signal. This is advantageous particularly when the conditions under which the respective sigma factor is active are not known. The consistency of results achieved by the in vivo and in vitro techniques provided reliable promoter classification as well as new data on the analyzed promoters.

\section{Materials and methods}

\section{Bacterial strains, plasmids, oligonucleotide primers and growth conditions}

The bacterial strains and plasmids used are listed in Table 1. The oligonucleotide primers are listed in Additional file 1: Table S1. E. coli DH5 $\alpha$ was used for cloning purposes. Wild-type (WT) C. glutamicum ATCC 13032 and its deletion derivatives C. glutamicum $\triangle \operatorname{sig} B, \triangle \operatorname{sig} E, \Delta s i g H$ and $\triangle$ sigM were used as hosts for testing the activities of promoters cloned in the promoter-test vector pEPR1. E. coli was cultivated aerobically in 500-ml flasks containing $80 \mathrm{ml}$ of 2xYT medium (Sambrook and Russel 2001) on a rotary shaker at $150 \mathrm{rpm}$ and $37^{\circ} \mathrm{C}$. C. glutamicum was cultivated in 500-ml flasks with $80 \mathrm{ml}$ of complete 2xYT medium (Sambrook and Russel 2001) or in minimal CGXII medium (Keilhauer et al. 1993) with protocatechuic acid at a concentration of $0.03 \mathrm{~g} / \mathrm{l}$ on a rotary shaker at $150 \mathrm{rpm}$ and $30{ }^{\circ} \mathrm{C}$. Kanamycin $(30 \mu \mathrm{g} / \mathrm{ml})$, tetracycline $(10 \mu \mathrm{g} / \mathrm{ml})$, spectinomycin $(200 \mu \mathrm{g} / \mathrm{ml})$ or ampicillin $(100 \mu \mathrm{g} / \mathrm{ml})$ was added to the selective media when appropriate.

\section{DNA manipulations}

DNA isolation, PCR, transformation of E. coli, DNA cloning and DNA analysis were performed using standard methods (Sambrook and Russel 2001). Genomic DNA from C. glutamicum was isolated as described (Eikmanns et al. 1994). C. glutamicum cells were transformed by electroporation (van der Rest et al. 1999).

Table 1 Strains and plasmids used in this study

\begin{tabular}{|c|c|c|}
\hline Strains & Relevant characteristics & Source/reference/application \\
\hline \multicolumn{3}{|l|}{ E. coli } \\
\hline $\mathrm{DH} 5 \mathrm{a}$ & Cloning host & Hanahan (1985) \\
\hline \multicolumn{3}{|l|}{ C. glutamicum } \\
\hline WT & ATCC 13032, wild type & ATCC \\
\hline$\Delta \operatorname{sig} B$ & Deletion in $\operatorname{sig} B$ & Larisch et al. (2007) \\
\hline$\triangle \operatorname{sig} E$ & Deletion in sigE & Park et al. (2008) \\
\hline$\Delta s i g H$ & Deletion in sigH & Zemanová et al. (2008) \\
\hline$\Delta \operatorname{sig} M$ & Deletion in sigM & Nakunst et al. (2007) \\
\hline \multicolumn{3}{|l|}{ Plasmids } \\
\hline pEC-XT99A & E. coli-C. glutamicum expression vector, $\mathrm{TC}^{\mathrm{R}}$, IPTG-inducible trc promoter & Kirchner and Tauch (2003) \\
\hline pEKEX3 & E. coli-C. glutamicum expression vector, $\mathrm{Sp}^{\mathrm{R}}, \mathrm{IPTG}$-inducible tac promoter & Hoffelder et al. (2010) \\
\hline pEPR1 & E. coli-C. glutamicum promoter-test vector, $\mathrm{Km}^{\mathrm{R}}$, promoterless gfpuv as a reporter & Knoppová et al. (2007) \\
\hline pEPR-P2sigA & pEPR1 with P2sigA & This work \\
\hline pEPR-Pfba & pEPR1 with Pfba & This work \\
\hline pEPR-Pcg2556 & pEPR1 with Pcg2556 & This work \\
\hline pEPR-Pcmt1 & pEPR1 with Pcmt1 & This work \\
\hline pEPR-PsigB & pEPR1 with PsigB & This work \\
\hline pEPR-PrshA & pEPR1 with PrshA & This work \\
\hline pEPR-PtrxB1 & pEPR1 with PtrxB1 & This work \\
\hline $\mathrm{pRLG770}$ & E. coli vector for in vitro transcription, $r r n B$ terminator, $A p^{R}$ & Ross et al. (1990) \\
\hline pRLG770P2sigA & pRLG770 with P2sigA & This work \\
\hline pRLG770Pfba & pRLG770 with Pfba & This work \\
\hline pRLG770Pcg2556 & pRLG770 with Pcg2556 & This work \\
\hline pRLG770Pcmt1 & pRLG770 with Pcmt1 & This work \\
\hline pRLG770 PsigB & pRLG770 with PsigB & This work \\
\hline pRLG770PrshA & pRLG770 with PrshA & This work \\
\hline pRLG770PtrXB1 & pRLG770 with PtrxB1 & This work \\
\hline
\end{tabular}




\section{Construction of the two-plasmid system for assignment of sigma factors to promoters in vivo}

We constructed a system for the in vivo identification of C. glutamicum promoters recognized by RNAP containing a particular sigma factor, which is based on the twoplasmid C. glutamicum strains similar to that developed for the identification of $\sigma^{\mathrm{E}}$-dependent promoters in $E$. coli (Rezuchova and Kormanec 2001). Promoters carried on the BamHI-PstI DNA fragments (amplified using PCR, oligonucleotide primers listed in Additional file 1: Table S1 and C. glutamicum chromosome as a template) were cloned in the promoter-test vector pEPR1 containing the promoterless gfpuv reporter gene (Knoppová et al. 2007). The genes encoding seven different sigma factors were cloned under the Ptrc promoter inducible with isopropyl- $\beta$-D1-thiogalactopyranoside (IPTG) in the expression vector pEC-XT99A (Kirchner and Tauch 2003). The sequences of all inserts were checked by sequencing. Analogous constructs carrying the sig genes under Ptac in the expression vector pEKEx3 (Hoffelder et al. 2010) were kindly supplied by Taniguchi and Wendisch (2015). There was negligible gene expression from pEC-XT99A without IPTG when we tested the model expression of the $g f p u v$ gene, whereas the expression of the gfpuv gene from pEKEx3 without IPTG addition was $20-30 \%$ of the maximum after IPTG induction (data not shown). C. glutamicum strains harboring both the pEPR1 + promoter and pEC-XT99A (or pEKEx3) + sig gene were obtained by successive transformation. The presence of correct plasmids in two-plasmid strains was checked by restriction enzyme analysis and PCR.

\section{In vivo promoter activity measurements}

To evaluate the effect of sig gene overexpression on the activity of a particular promoter, the assay was performed as follows: The two-plasmid strain carrying the sig gene in the expression vector and a promoter in the promoter test vector pEPR1 was cultivated aerobically in $80 \mathrm{ml}$ $2 \mathrm{xYT}$ medium at $30{ }^{\circ} \mathrm{C}$. IPTG $(1 \mathrm{mM})$ was added to the culture when $\mathrm{OD}_{600}$ reached 1 to overexpress a particular sig gene. Samples of the culture were then taken at various time points (mostly 0, 3, 6 and $24 \mathrm{~h}$ ). The cells were washed with phosphate-buffered saline $\mathrm{pH}$ 8.0 (PBS) (Sambrook and Russel 2001) with $1 \mathrm{mM}$ phenylmethylsulfonyl fluoride and $2 \mathrm{mM}$ 2-mercaptoethanol, concentrated in $0.5 \mathrm{ml}$ of cell suspension to a final $\mathrm{OD}_{600}=24$ in PBS and disrupted with a FastPrep homogenizer (MP Biomedical) $(3 \times 60 \mathrm{~s}$ at speed $6 \mathrm{~m} / \mathrm{s}$ with Lysing Matrix B in 2-ml tubes). After centrifugation (20 min at $15,000 \times g)$ the fluorescence of the cell-free extract was measured with a Saphire 2 microplate spectrophotometer (Tecan; excitation wavelength, $397 \mathrm{~nm}$; emission wavelength $509 \mathrm{~nm}$ ). Protein concentration in the extract was determined by Bradford assay and promoter activity was expressed in arbitrary units/mg protein. Cells harboring the pEPR1 construct and the expression vector without a sig gene were used as a control.

\section{In vitro transcription assay}

The multiple-round in vitro transcription assay was in principle performed using the recently described system (Holátko et al. 2012). Both the RNAP core and sigma factors from C. glutamicum were isolated as described previously, using the C. glutamicum rpoC-H8 strain producing the RNAP core and E. coli BL21 (DE3) with pET$22 \mathrm{~b}(+)$ constructs producing individual C. glutamicum $\sigma$ factors (Holátko et al. 2012; Šilar et al. 2016). The reconstituted holo-RNAP was prepared by mixing the RNAP core $(100 \mathrm{nM})$ and the respective sigma factor in a molar ratio of $1: 30$ and incubating for $10 \mathrm{~min}$ at $37^{\circ} \mathrm{C}$. The transcription mixture contained ATP, CTP and GTP $(200 \mu \mathrm{M}$ each), $10 \mu \mathrm{M}$ UTP and $3 \mu \mathrm{M} \alpha^{32}$ P-UTP. The reaction was run for $10 \mathrm{~min}$ at $37^{\circ} \mathrm{C}$. All promoter fragments (approx. $70 \mathrm{nt}$ ) were cloned in the vector pRLG770 (using EcoRI and HindIII sites) in such a way that a 150-nt transcript (terminated at the $r r n B$ terminator) was produced by the in vitro transcription (Holátko et al. 2012). The produced radiolabeled transcripts were separated by electrophoresis on $5.5 \%$ polyacrylamide gels (PAGE) with $7 \mathrm{M}$ urea. The transcripts in dried gels were detected by exposure to phosphorimaging screen (6-24 h), followed by scanning with a Molecular Imager FX (BIO-RAD). Electrophoresis gel data from the imaging systems were visualized and analyzed with Quantity One 1-D analysis software. All assays were performed at least three times and consistent results were obtained. Representative results are shown.

\section{Tryptic digestion of in-gel proteins and liquid} chromatography-tandem mass spectrometry (LC-MS/MS) analysis

The proteins extracted from the C. glutamicum cells disrupted by sonication were run in SDS-PAGE gels. The gel slice containing a bend corresponding to $25 \mathrm{kDa}$ protein was digested with trypsin (100 ng; Promega) overnight in a cleavage buffer containing $25 \mathrm{mM}$ 4-ethylmorpholine acetate, and the resulting peptides were subjected to an LCMS/MS analysis using collision-induced fragmentation in a Synapt G2Si mass spectrometer (Waters) coupled to an ACQUITY UPLC M-class system (HSS T3 $1.8 \mu$ m column, $75 \mu \mathrm{m} \times 150 \mathrm{~mm}$ ). For protein identification, the tandem mass spectra were searched against the NCBI bacterial database using an in-house Mascot search engine.

\section{Results}

$\sigma^{\mathrm{H}}$-dependent promoters: PrshA and PtrxB1

$\sigma^{\mathrm{H}}$ is the most studied ECF sigma factor, which forms a transcriptional regulatory network enabling the $C$. 
glutamicum cell to respond to temperature, oxidative and growth-phase induced stresses (Busche et al. 2012; Ehira et al. 2009; Toyoda and Inui 2016b; Toyoda et al. 2015). Due to its role in the expression of the genes encoding regulatory proteins and prominent position in the regulatory network, it is a likely candidate for a global regulator in C. glutamicum (Schröder and Tauch 2010). The rshA gene that encodes the anti- $\sigma^{\mathrm{H}}$ factor was localized immediately downstream of the $\mathrm{sigH}$ gene and forms an operon with sigH (Busche et al. 2012). The rshA gene is transcribed from PrshA (internal to $\operatorname{sigH}$ ) in addition to the PsigH promoters found upstream of the operon (Busche et al. 2012). PrshA sequence elements - 35 GGAAGA and -10 GTTAAA (Fig. 1a) conform to the consensus of $\sigma^{\mathrm{H}}$-dependent promoters, however the expression of rshA was not found to be up-regulated in C. glutamicum by the microarray analysis (Ehira et al. 2009). In vitro transcription assays resulted in a single specific band produced by RNAP with $\sigma^{\mathrm{H}}$ (Fig. 1b). The in vivo analysis with pEC-XT99A and pEPR1 carrying the sig genes and $\operatorname{Prsh} A$, respectively, in the C. glutamicum $\Delta$ sigH strain unequivocally demonstrated that $\operatorname{Prsh} A$ is controlled by $\sigma^{\mathrm{H}}$ (Fig. 1c). Very similar results were obtained when the C. glutamicum WT was used (data not shown).

The promoter of the $\operatorname{tr} x B 1$ gene was first described as $\sigma^{\mathrm{M}}$-dependent (Nakunst et al. 2007) but as $\sigma^{\mathrm{H}}$-dependent in another study (Busche et al. 2012). The trxB1 gene encodes a disulfide oxido-reductase that catalyzes a wide spectrum of redox reactions in the cell and is involved in oxidative stress response. A transcriptional start site of $\operatorname{tr} x B 1$ was determined by RACE (Nakunst et al. 2007) and later confirmed by RNA sequencing (Pfeifer-Sancar et al. 2013). A single promoter of the gene with the key promoter elements - 35 GGAATA and -10 GTTGGT (Fig. 2a) was thus localized. The core conserved sequence motifs -35 GGAA and -10 GTT match the proposed consensus sequences of both $\sigma^{\mathrm{M}}$-specific (Nakunst et al. 2007) and $\sigma^{\mathrm{H}}$-specific (Busche et al. 2012) promoters. The in vitro transcription assay showed that only $\sigma^{\mathrm{H}}$ recognized PtrxB1 (Fig. 2b).

In vivo analysis using the two-plasmid system in the C. glutamicum $\Delta s i g H$ strain also clearly indicated that it was only the overexpression of $\sigma^{\mathrm{H}}$ that triggered a sharp increase in the PtrxB1 activity (Fig. 2c). Very similar results were obtained when $C$. glutamicum WT was used (data not shown). To detect whether some other stress sigma factor at least weakly contributes to PtrxB1 activity in vivo, the effects of deletions in the genes $\operatorname{sigH}$, sigM and sigE on the PtrxB1 activity during growth were tested. As shown in Fig. 2d, the reporter fluorescence measured with strains carrying only pEPR1-PtrxB1 remained at the level of the control (WT) in the $\triangle$ sigM and $\Delta s i g E$ strains, whereas it was approximately 14 -fold lower in the $\Delta s i g H$ strain and essentially at the same level as that obtained with the strain only carrying the empty vector pEPR1. We therefore concluded that the PtrxB1 promoter is $\sigma^{\mathrm{H}}$-specific.

\section{$A \sigma^{\mathrm{E}}$ - and $\sigma^{\mathrm{H}}$-dependent promoter: $\mathrm{Psig} B$}

Next, we tested the effect of the $\operatorname{sig} E$ gene deletion on the transcriptional activity of the $\operatorname{cg} 1266$ gene. This gene was

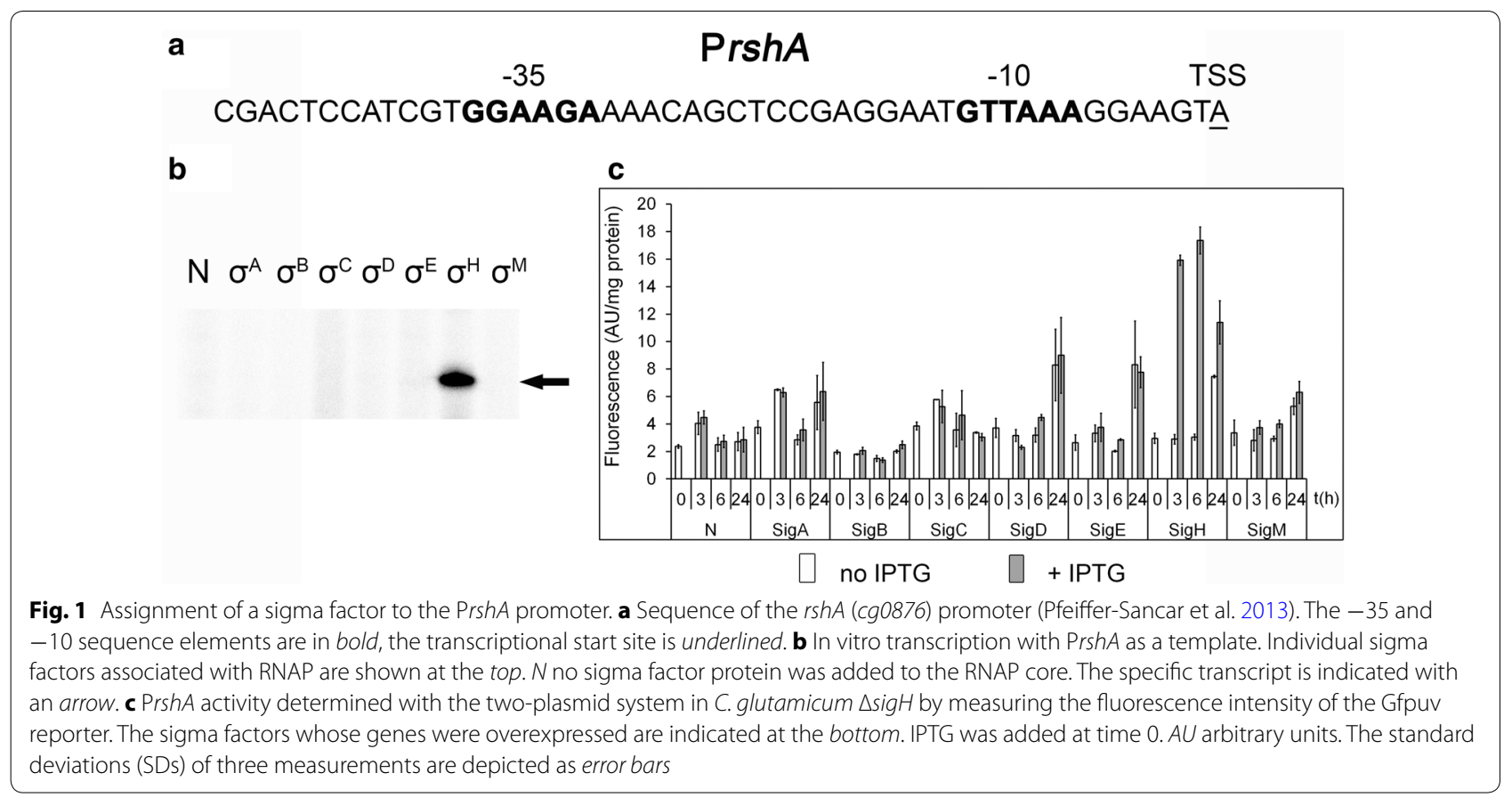


a

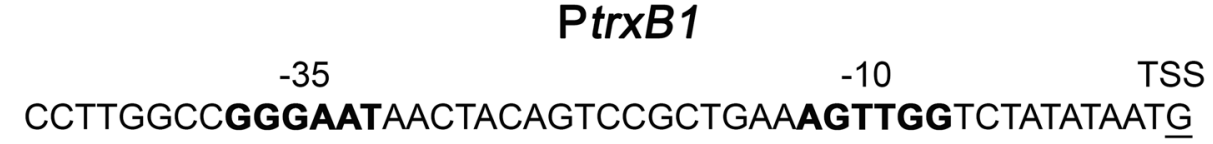

b

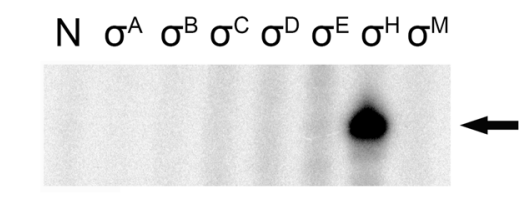

d

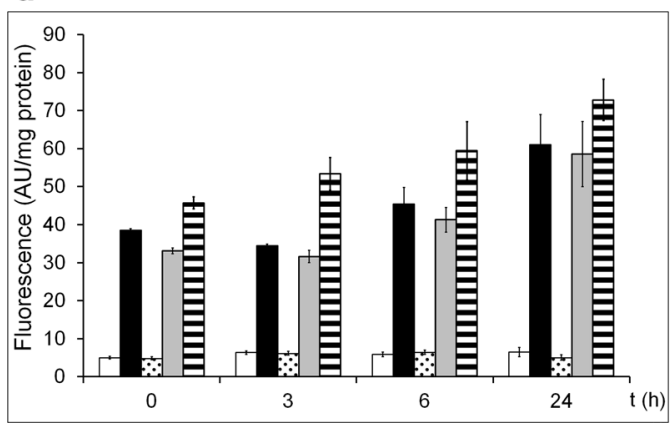

c

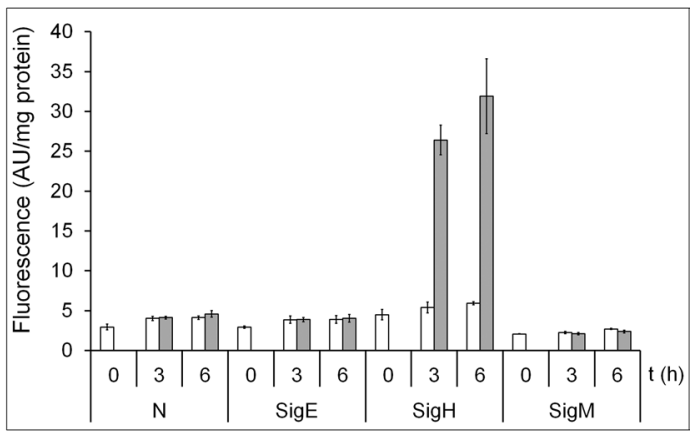

no IPTG

+ IPTG
WT/pEPR1

WT/pEPR-PtrxB1

. $\Delta s i g H / p E P R-P t r x B 1$

$\triangle \operatorname{sigM/pEPR-PtrxB1}$

目 $\Delta s i g E / p E P R-P t r \times B 1$

Fig. 2 Assignment of a sigma factor to the PtrxB1 promoter. a Sequence of the PtrxB1 promoter (Nakunst et al. 2007). The -35 and -10 sequence elements are in bold, the transcriptional start site is underlined. $\mathbf{b}$ In vitro transcription with PtrXB1 as a template. Individual sigma factors associated with RNAP are shown at the top. N no sigma factor was added to the RNAP core. The specific transcript is indicated with an arrow. $\mathbf{c}$ PtrxB1 activity determined with the two-plasmid system in C. glutamicum $\triangle$ sigH by measuring the fluorescence intensity of the Gfpuv reporter. The sigma factors whose genes were overexpressed are indicated at the bottom. IPTG was added at time 0. d PtrxB1 activity in C. glutamicum $\triangle$ sigH, $\triangle$ sigM or $\triangle$ sigE strains carrying a single plasmid, pEPR-PtrxB1. The values for the WT strain carrying the empty vector pEPR1 are shown as a control. AU arbitrary units. The SDs of three measurements are depicted as error bars

suggested to be $\sigma^{\mathrm{E}}$-dependent (Park et al. 2008) but we did not detect any potential $\sigma^{\mathrm{E}}$-dependent promoter (data not shown). Based on the similarity of the promoter region of the C. glutamicum sigB gene to the Mycobacterium tuberculosis sigB promoter (controlled by $\sigma^{\mathrm{E}}$ and $\sigma^{\mathrm{H}}$ ) it was suggested that the $C$. glutamicum sigB may be under the control of $\sigma^{\mathrm{E}}$ (Halgasova et al. 2002). The $\operatorname{sig} B$ gene exhibited a higher level of transcription when $s i g H$ was overexpressed and was therefore considered to be $\sigma^{\mathrm{H}}$-dependent (Ehira et al. 2009). The PsigB sequence elements - 35 GGAA and -10 GTT conform to the consensus of $\sigma^{\mathrm{H}}$-dependent promoters, however, the $\sigma^{\mathrm{H}}$ dependence was not proved by microarrays when $\Delta s i g H$ (Ehira et al. 2009) or $\Delta r s h A$ strains (Busche et al. 2012) were used. This gave us a hint that still another sigma factor is involved in $\operatorname{sig} B$ transcription. We carried out the in vitro transcription assays with all seven C. glutamicum sigma factors. Bands were detected when RNAP $+\sigma^{E}$ or $\sigma^{\mathrm{H}}$ were applied (Fig. 3b). Specific band intensities based on three in vitro assays were quantified using Quantity One 1-D software, which showed that approximately 5.5-fold more transcript was produced with $\mathrm{RNAP}+\sigma^{\mathrm{E}}$ than with RNAP $+\sigma^{\mathrm{H}}$. The results of in vivo analysis using the two-plasmid system in the C. glutamicum WT suggested that the transcription from PsigB is induced by the overexpression of $\sigma^{\mathrm{H}}$ and significantly less by the overexpression of $\sigma^{E}$ (data not shown). To test whether RNAP $+\sigma^{E}$ can initiate transcription from PsigB in vivo more efficiently when $\sigma^{\mathrm{H}}$ does not compete with $\sigma^{\mathrm{E}}$, we used the two-plasmid assay in the $\Delta s i g H$ strain with all seven sigma factors. As shown in Fig. 3c, the overexpression of both $\sigma^{\mathrm{H}}$ and $\sigma^{\mathrm{E}}$ increased expression of the $g f p u v$ reporter gene from PsigB. These results clearly demonstrated that RNAP $+\sigma^{\mathrm{E}}$ can drive transcription from PsigB but $\sigma^{\mathrm{H}}$ competes with $\sigma^{\mathrm{E}}$ for RNAP or binding to the promoter.

\section{A $\sigma^{C}$-dependent promoter: Pcg2556}

Expression of the genes regulated by $\sigma^{\mathrm{C}}$ has recently been described (Toyoda and Inui 2016a). We selected the 
a

PsigB

$-35 \quad-10 \quad$ TSS

CAAAAGCGCTTGGGAACTTTTTGTGGAAGCAGTCCGTTGAACCTCTTE

b

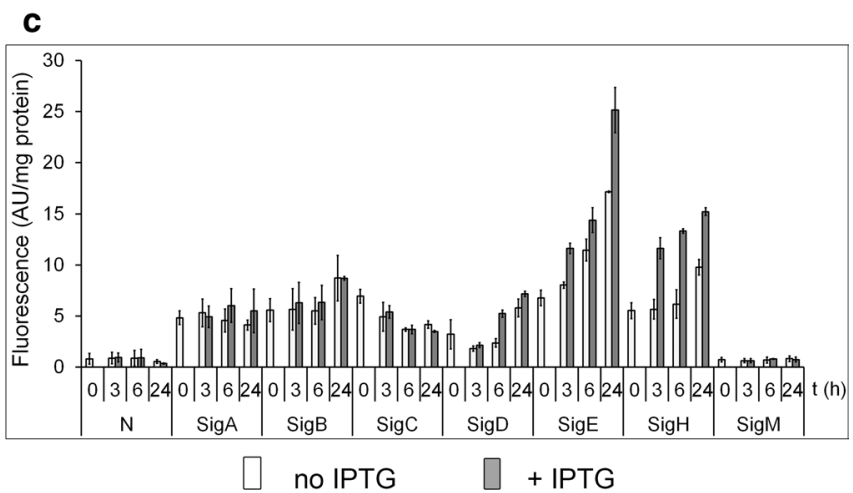

Fig. 3 Assignment of sigma factors to the PsigB promoter. a Sequence of the PsigB promoter (Halgasova et al. 2001). The assumed -35 and -10 sequence elements are in bold, the transcriptional start site is underlined. $\mathbf{b}$ In vitro transcription with PsigB as a template. Individual sigma factors associated with RNAP are shown at the top. $N$ no sigma factor protein was added to the RNAP core. The specific transcripts are indicated with an arrow. c PsigB promoter activity determined using the two-plasmid C. glutamicum $\triangle$ sigH by measuring the fluorescence intensity of the Gfpuv reporter. The sigma factors whose genes were overexpressed are indicated at the bottom. IPTG was added at time 0 . AU arbitrary units. The SDs of three measurements are depicted as error bars

promoter of the C. glutamicum ATCC 13032 cg2556 gene encoding an uncharacterized iron-regulated membrane protein (corresponding to the cgR_2208 gene in the sequence of C. glutamicum R; Toyoda and Inui 2016a) to test sigma dependency of its promoter. In vitro transcription assays confirmed that $c g 2556$ transcription is $\sigma^{\mathrm{C}}$ specific (Fig. 4b). The in vivo two-plasmid assay produced the same result (Fig. 4c).

\section{A $\sigma^{D}$-dependent promoter: Pcmt 1}

RNA sequencing studies suggested that there is a group of genes which are $\sigma^{\mathrm{D}}$-dependent (Busche and Kalinowski, unpublished). We selected the promoter of cmt1 (encoding trehalose corynomycolyl transferase) to test its $\sigma^{\mathrm{D}}$ dependency. In vitro transcription assays only provided a specific band when RNAP $+\sigma^{\mathrm{D}}$ was used (Fig. 5b). The in vivo two-plasmid analyses in the WT strain using all ECF $\sigma$ factors confirmed that Pcmt1 is $\sigma^{\mathrm{D}}$-dependent (Fig. 5c). To date no consensus sequence of the promoters recognized by RNAP $+\sigma^{\mathrm{D}}$ has been proposed. The involvement of the $c m t 1$ gene and other potentially $\sigma^{\mathrm{D}}$-dependent genes in stress response is currently being studied.

\section{The quest for a $\sigma^{\mathrm{M}}$-dependent promoter}

The sigma factor $\sigma^{\mathrm{M}}$ was found to be involved in oxidative stress response in C. glutamicum. The $\sigma^{\mathrm{M}}$ dependent transcription of 23 genes was suggested by using microarray analyses of the C. glutamicum WT and $\triangle$ sigM strain (Nakunst et al. 2007). Promoter sequences of four of these genes (PtrxB, PtrxC, PtrxB1 and PsufR) were localized by determination of the respective transcriptional start sites (TSSs). Three of the genes $\operatorname{tr} x B$, $\operatorname{tr} x \mathrm{C}$ and sufR) were found to be $\sigma^{\mathrm{H}}$-dependent by Ehira et al. (2009). We analyzed all these four promoters using both in vivo and in vitro techniques. In all cases only $\sigma^{\mathrm{H}}$ dependent transcription was detected (data not shown). We were thus unable to confirm the $\sigma^{\mathrm{M}}$ dependency of any of these promoters. The failure to detect an in vitro transcript with RNAP $+\sigma^{\mathrm{M}}$ might be due to the limitations of the technique used. In contrast to all other $\sigma$ factors purified for the in vitro assays, most of the $\sigma^{\mathrm{M}}$ protein was detected in the insoluble fraction after its isolation from $E$. coli extracts using affinity chromatography (data not shown). Various modifications of the protocol did not improve the ratio of the soluble/insoluble fraction. The $\sigma^{\mathrm{M}}$ protein was therefore denatured and renatured. Since no $\sigma^{\mathrm{M}}$-specific promoter was detected by the in vitro assay, there is a possibility that the renatured $\sigma^{\mathrm{M}}$ was not functional in vitro. Another reason for failing to prove $\sigma^{\mathrm{M}}$-dependent transcription using the in vitro transcription may be missing activators. To test whether $\sigma^{\mathrm{M}}$ is present in the C. glutamicum $\triangle$ sigM cells carrying the pEC-XT99A vector with cloned sigM after IPTG induction in the in vivo assay, we analyzed the proteins of the cell extract by LC-MS/MS. Among other 


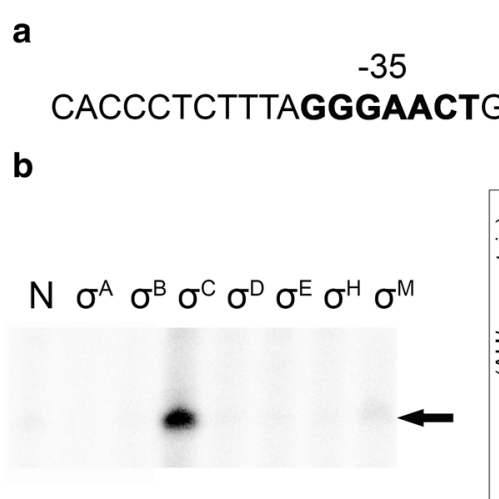

Pcg2556

$-10$

TSS

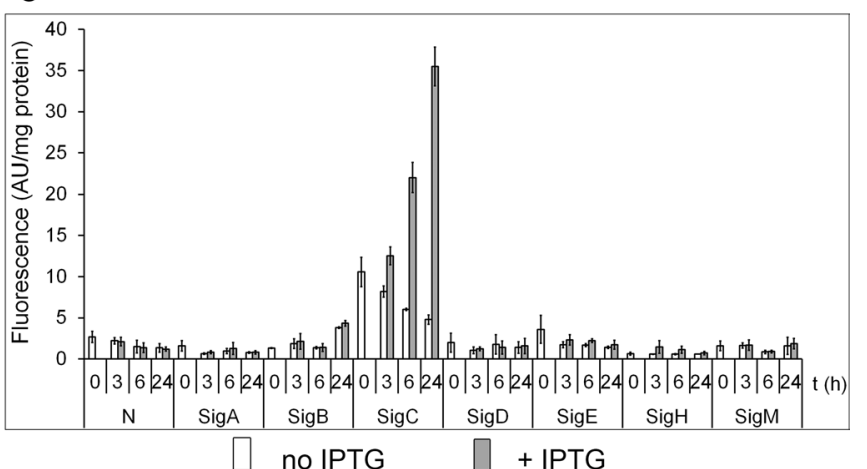

Fig. 4 Assignment of a sigma factor to the Pcg2556 promoter. a Sequence of the cg2556 (cgR_2208) promoter (Toyoda and Inui $2016 a$ ). The - 35 and -10 sequence elements are in bold, the transcriptional start site is underlined. $\mathbf{b}$ In vitro transcription with Pcg 2556 as a template. Individual sigma factors associated with RNAP are shown at the top. N no sigma was added to the RNAP core. The specific transcript is indicated with an arrow. c Pcg2556 activity determined with the two-plasmid system in C. glutamicum WT by measuring the fluorescence intensity of the Gfpuv reporter. The sigma factors whose genes were overexpressed are indicated at the bottom. The SDs of three measurements are depicted as error bars

a

Pcmt1

TSS

GTAAAGCGCCTGTTAACGTAATAGCTTGAAATATAGATGTAAATTAAA

b

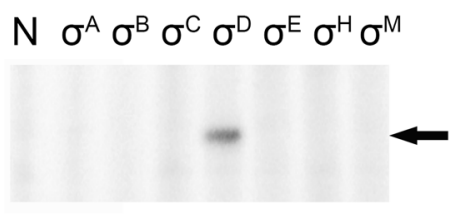

C

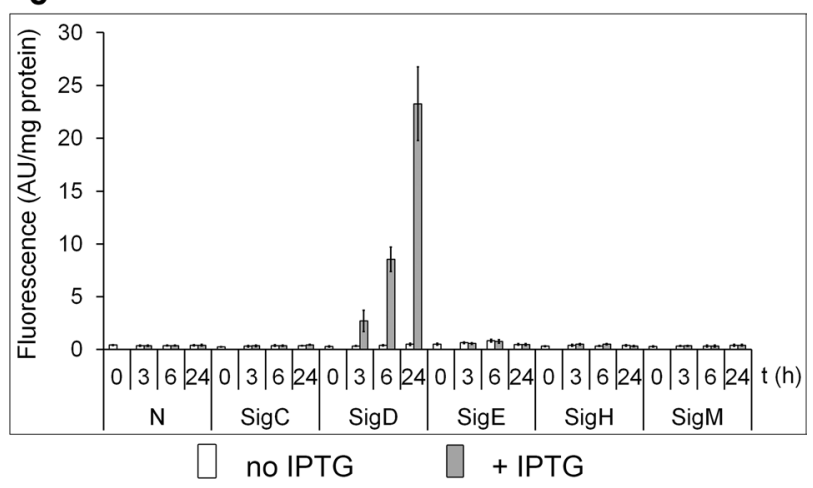

Fig. 5 Assignment of a sigma factor to the Pcmt1 promoter. a Sequence of the $\mathrm{cmt} 1$ promoter region. $\mathbf{b}$ In vitro transcription with $\mathrm{P} c m+1$ as a template. Individual sigma factors associated with RNAP are shown at the top. N no sigma factor was added to the RNAP core. The specific transcript is indicated with an arrow. CPCmt1 promoter activity determined with the two-plasmid system in C. glutamicum WT by measuring the fluorescence intensity of the Gfpuv reporter. The sigma factors whose genes were overexpressed are indicated at the bottom. IPTG was added at time 0. AU arbitrary units. The SDs of three measurements are depicted as error bars

proteins the presence of the $\sigma^{\mathrm{M}}$ protein was confirmed by the identification of four peptides which covered $22 \%$ of the $\sigma^{\mathrm{M}}$ protein sequence (Additional file 1: Table S2). Thus, the failure to demonstrate $\sigma^{\mathrm{M}}$ dependency for any of these promoters in vivo was not due to the absence of $\sigma^{\mathrm{M}}$ expression. The elucidation of $\sigma^{\mathrm{M}}$ function and finding $\sigma^{\mathrm{M}}$-controlled promoters needs further investigation.

\section{A $\sigma^{\mathrm{A}}$-dependent promoter: $\mathrm{P} 2 \operatorname{sig} \mathrm{A}$}

It is difficult to reliably prove that a promoter is $\sigma^{\mathrm{A}}$ specific in C. glutamicum since $\sigma^{\mathrm{A}}$ is present in the cell during all growth phases and under most conditions, and deletion of the sigA gene would be lethal. The promoters are usually considered "vegetative" or "housekeeping" if their -35 and -10 promoter element sequences 
match the generally accepted consensus of housekeeping promoters and the respective genes are expressed during exponential growth under optimal conditions. We selected the P2sigA promoter of the sigA gene encoding the primary sigma factor to test whether the designed methods can prove its assumed $\sigma^{\mathrm{A}}$ dependency. P2sigA was localized by the determination of sigA TSS (Halgasova et al. 2001). According to the transcriptional profile of the sigA gene (expressed mainly in the exponential growth phase; Larisch et al. 2007) it is supposed to be $\sigma^{\mathrm{A}}$-dependent. The sequences of the key promoter elements, -35 GTGACA and -10 TATAAT (Fig. 6a), are closely similar to the defined consensus sequence of the $\sigma^{\mathrm{A}}$-dependent promoters in C. glutamicum (Pátek and Nešvera 2011; Pfeifer-Sancar et al. 2013) and $\sigma^{70}$ dependent promoters in E. coli (Lisser and Margalit 1993). The in vitro transcription assays showed that RNAP $+\sigma^{\mathrm{A}}$, but also RNAP $+\sigma^{\mathrm{B}}$ provide specific transcripts with the P2sigA promoter as a template (Fig. 6b). The values of fluorescence obtained from the two-plasmid system in C. glutamicum WT using pECXT-99A with $\operatorname{sig} A$ or $\operatorname{sig} B$ were lower than those obtained with other sigma factors and the control (empty pECXT-99A) as well. We also observed this phenomenon for other $\sigma^{\mathrm{A}}$ and $\sigma^{B}$-dependent promoters (data not shown). To see the effect of $\sigma$ factor gene overexpression more clearly, the fluorescence intensity values were expressed as differences between the fluorescence at the sampling time $(3,6,24 \mathrm{~h})$ and the fluorescence at time 0 (Fig. 6c). Only the overexpression of sigA (from pEC-XT99A) resulted in an increase in P2sigA promoter activity in both the exponential and stationary phase, whereas the overexpression of other sigma factors did not change its activity, or even decreased it $\left(\sigma^{\mathrm{H}}\right)$ (Fig. 6c). This effect may be due to the competition of $\sigma^{\mathrm{H}}$ with $\sigma^{\mathrm{A}}$ for RNAP. Similarly, the low activity of P2sigA when $\sigma^{B}$ was overexpressed could be the consequence of the competition of $\sigma^{\mathrm{A}}$ with $\sigma^{B}$ for RNAP or binding the respective holoenzyme $\left(\mathrm{RNAP}+\sigma^{\mathrm{A}}\right.$ or RNAP $\left.+\sigma^{\mathrm{B}}\right)$ to the promoter. We conclude that P2sigA is predominantly $\sigma^{\mathrm{A}}$-dependent and may probably also be active with $\sigma^{\mathrm{B}}$ in vivo under specific conditions (e.g. stress and the stationary phase).

\section{$A \sigma^{B}$ - dependent promoter: $\mathrm{Pfba}$}

The $f b a$ gene (encoding fructose 1,6-bisphosphate aldolase) was found to be downregulated in the $\operatorname{sig} B$ deletion strain both under conditions of oxygen deprivation and during aerobic cultivation (Ehira et al. 2008). The gene is involved in glucose metabolism and is mostly expressed during exponential growth whereas its expression decreases in the transition phase. The sequences of the key promoter elements (Ehira et al. 2008), -35 CGACAA and -10 CATAAT (Fig. 7a) are very similar to those of the proposed consensus of $\sigma^{\mathrm{A}}$-specific promoters (Pátek and Nešvera 2011; Pfeifer-Sancar et al. 2013). In vitro transcription assays showed that both $\sigma^{\mathrm{A}}$ and $\sigma^{B}$ with RNAP produce specific signals with $\mathrm{P} f b a$ (Fig. 7b). In vivo analysis using the two-plasmid system in the C. glutamicum WT strain with the expression vector pEC-XT99A carrying cloned sig genes did not provide an increase in promoter activity with any $\sigma$ factor (data not shown). However, an alternative system

a

$\mathrm{P} 2$ sigA

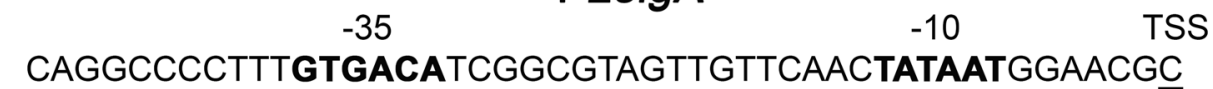

b

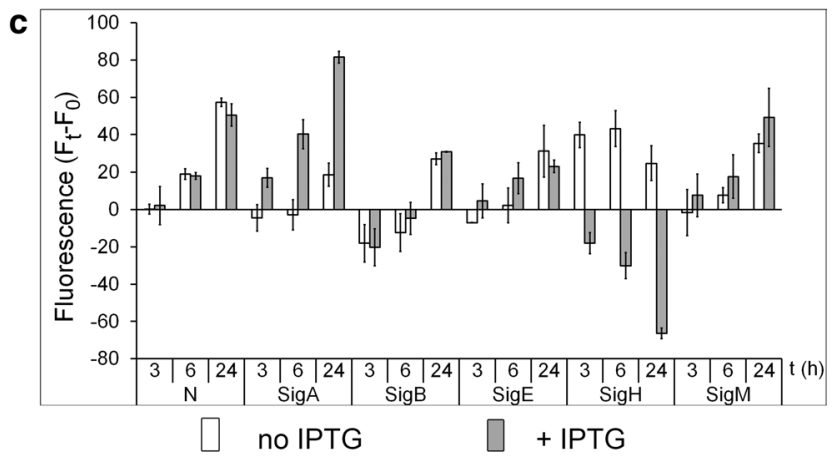

Fig. 6 Assignment of sigma factors to the P2sigA promoter. a Sequence of the P2sigA promoter (Halgasova et al. 2001). b In vitro transcription with P2sigA as a template. Individual sigma factors associated with RNAP are shown at the top. The specific transcripts are indicated with an arrow. c P2sigA promoter activity determined with the two-plasmid system in C. glutamicum WT by measuring the fluorescence intensity of the Gfpuv reporter. $F_{t}-F_{0}$ is the difference between the fluorescence at the sampling time $(3,6,24 \mathrm{~h}$ ) and the fluorescence at time 0 (before sigma gene induction). The sigma factors whose genes were overexpressed are indicated at the bottom. The SDs of three measurements are depicted as error bars 
a

Pfba

-35 $-10 \quad$ TSS

AGATATCACACGACAAAAGTTGAGTGATGCAGGCATAATTGGCTATGG

b

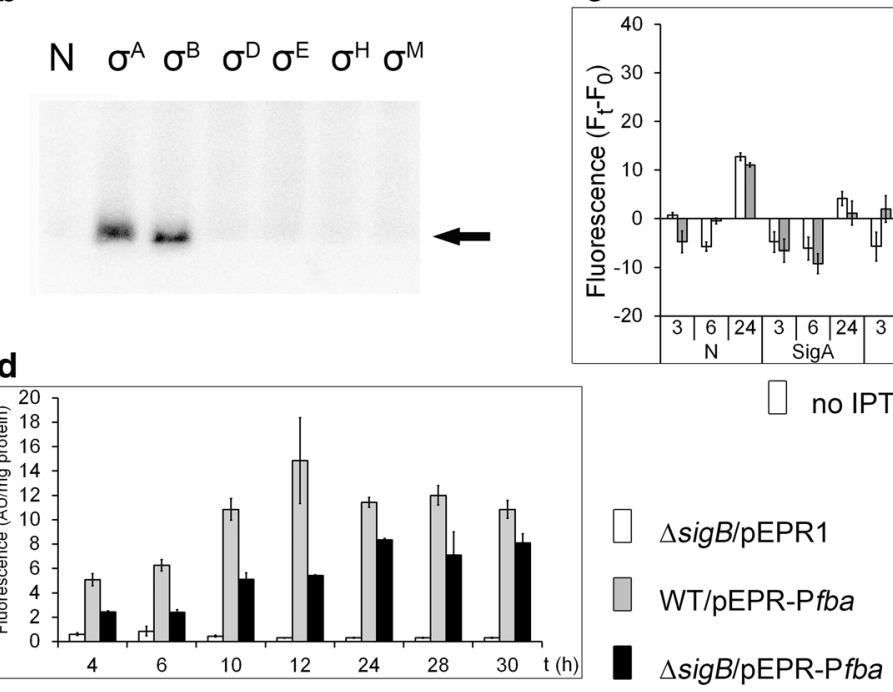

Fig. 7 Assignment of sigma factors to the Pfba promoter. a Sequence of the Pfba promoter (Ehira et al. 2008). b In vitro transcription with Pfba as a template. Individual sigma factors associated with RNAP are shown at the top. The specific transcripts are indicated with an arrow. c Pfba promoter activity determined with the two-plasmid system in C. glutamicum WT (with the sig-constructs in the expression vector pEKEx3) by measuring the fluorescence intensity of the Gfpuv reporter. $F_{t}-F_{0}$ is the difference between the fluorescence at the sampling time $(3,6,24 \mathrm{~h})$ and the fluorescence at time 0 (before sigma gene induction). The sigma factors whose genes were overexpressed are indicated at the bottom. IPTG was added at time $0 . \mathbf{d}$ Activity of Pfba in C. glutamicum WT and $\triangle$ sigB. C. glutamicum $\triangle$ sigB with empty vector pEPR1 served as a control. The SDs of three measurements are depicted as error bars

utilizing the expression vector pEKEx3 with cloned sig genes and $\mathrm{pEPR} 1-\mathrm{P} f b a$ proved that $\mathrm{P} f b a$ is recognized by $\sigma^{B}$ under the conditions used (Fig. 7c). A slight increase was also observed with $\sigma^{\mathrm{E}}$. Since we found that the promoter of the $\operatorname{sig} B$ gene is transcribed by RNAP $+\sigma^{\mathrm{E}}$, this effect may be explained by the indirect effect of $\operatorname{sig} E$ overexpression. Activity of $\mathrm{P} f b a$ was further tested in the single-plasmid strains C. glutamicum WT and $\triangle$ sigB carrying pEPR1-P $f b a$. The activity of $\mathrm{P} f b a$ was significantly lower in the $\triangle \operatorname{sig} B$ strain than in WT, but was still higher than the activity exhibited by the $\triangle \operatorname{sig} B$ strain carrying an empty vector pEPR1 (Fig. 7d). The observed substantial residual activity of $\mathrm{P} f b a$ in $C$. glutamicum $\triangle$ sigB is in agreement with the recognition of this promoter by $\sigma^{\mathrm{A}}$ proved in vitro. These results suggest that transcription from $\mathrm{P} f b a$ is mainly driven by RNAP $+\sigma^{\mathrm{B}}$ even during exponential growth, and $\sigma^{\mathrm{A}}$ may substitute for $\sigma^{\mathrm{B}}$ under some specific conditions.

\section{Discussion}

Expression of sigma factor genes in bacteria is organized into cascades or networks (Qiu et al. 2013; Cho et al. 2014). Therefore, it is sometimes difficult to distinguish between the direct and indirect effects of the overexpression or deletion of sig genes in studies of the dependence of promoters on sigma factors. The genome-level in vivo approaches to analyzing $\sigma$-specific regulons using microarrays or ChIP-chip techniques may therefore be negatively affected by these regulatory interactions.

Thus the results of in vivo techniques may be overshadowed by secondary effects caused by the cascade or network nature of $\sigma$ regulation, the competition of $\sigma$ factors for RNAP and promoters, or the activities of transcriptional regulators. In contrast, the in vitro reaction, in which the DNA template is transcribed from a single promoter by a purified RNAP core with a single $\sigma$ factor, can avoid such interactions. An in vitro transcription system which mimics many features of in vivo transcription thus provides results that are free of indirect effects. On the other hand, the in vitro transcription may produce some artifacts, since some promoters may require activators or appropriate DNA conformation (superhelicity) or other type of physiological control for their natural activity.

To compensate for the drawbacks of each of these approaches, both in vivo and in vitro methods should be 
applied for the analysis of sigma factor-promoter interactions. By combining the results of in vitro and in vivo experiments, one can achieve an unambiguous assignment of sigma factors to promoters.

The main aim of this work was to integrate the results of our newly developed in vitro and in vivo techniques so that we can reliably classify individual promoters according to their $\sigma$ factor dependency. This approach proved to be useful, and we were able to find a representative example of a promoter for every sigma factor with the exception of $\sigma^{\mathrm{M}}$. The achieved results show that the system can produce data that is almost free of secondary effects. We were also able to convincingly document the recognition overlap of two $\sigma$ factors at a single promoter $\left(\sigma^{\mathrm{A}} / \sigma^{\mathrm{B}}, \sigma^{\mathrm{E}} /\right.$ $\left.\sigma^{\mathrm{H}}\right)$.

The $r s h A$ gene, which is located immediately downstream of $s i g H$, encodes the anti- $\sigma^{\mathrm{H}}$ factor. The gene is transcribed together with the $\operatorname{sig} H$ from $\sigma^{\mathrm{A}}$-dependent promoters and separately as a monocistronic rsh $A$ transcript from $\operatorname{Prsh} A$ which was proposed to be $\sigma^{\mathrm{H}}$ dependent (Busche et al. 2012). This arrangement probably ensures the rapid shutdown of the $\sigma^{\mathrm{H}}$-dependent stress response as soon as the stress conditions are over. We have now confirmed by both in vivo and in vitro techniques that $\operatorname{Prsh} A$ is a $\sigma^{\mathrm{H}}$-specific promoter (Fig. 1). Similarly, PtrxB1 was shown to be a $\sigma^{\mathrm{H}}$-specific promoter (Fig. 2). Neither the in vitro nor in vivo assay generated a signal with any other sigma factor. The PtrxB1 promoter activity measurements using the $\triangle \operatorname{sig} H, \triangle \operatorname{sig} M$ and $\triangle \operatorname{sig} E$ strains showed that $\operatorname{sig} H$ deletion completely eliminated its activity, whereas the $\operatorname{sig} M$ and $\operatorname{sig} E$ deletions did not change or even increased its activity (Fig. 2d). The activities of PtrxB, PtrxC and PsufR that were also predicted to be $\sigma^{\mathrm{M}}$-dependent in a study based on a sigM deletion strain (Nakunst et al. 2007) but $\sigma^{\mathrm{H}}$-dependent according to the disruption or overexpression of $\operatorname{sigH}$ (Ehira et al. 2009) were completely eliminated in $\Delta s i g H$ as well (data not shown). The in vivo two-plasmid system also showed that PtrxB, PsufR and PtrxC are $\sigma^{\mathrm{H}}$-specific, although the presence of $\sigma^{\mathrm{M}}$ in the C. glutamicum cells after the induction of $\operatorname{sig} M$ expression was proved by mass spectrometry.

We have recently shown that the promoters $\mathrm{P} 1 \mathrm{clgR}$, P2dnaK and P2dnaJ2 are recognized by both $\sigma^{\mathrm{E}}$ and $\sigma^{\mathrm{H}}$ (Šilar et al. 2016). To date, no exclusively $\sigma^{\mathrm{E}}$-specific $C$. glutamicum promoter has been reported. PsigB was also found to be controlled by $\sigma^{\mathrm{E}}$ and $\sigma^{\mathrm{H}}$ in this study, just like the M. tuberculosis sigB promoter (Rodrigue et al. 2006). This is in agreement with suggestions that $C$. glutamicum $\sigma^{\mathrm{B}}$ plays a role as a general stress response $\sigma$ factor and as a back-up housekeeping $\sigma$ for stress conditions (Halgasova et al. 2002; Larisch et al. 2007).
The $\sigma^{\mathrm{C}}$-dependent promoters seem to be very specific and are probably recognized exclusively by $\sigma^{\mathrm{C}}$, although their consensus sequence elements - 35 GGGAACT and -10 CGACTA (Toyoda and Inui 2016a) contain the same -35 tetramer GGAA as $\sigma^{\mathrm{H}}$-dependent promoters. Both in vitro and in vivo methods clearly confirmed the assignment of $\sigma^{\mathrm{C}}$ to P $c$ 2556. Similarly, the two methods coincidentally indicated that the Pcmt1 promoter is $\sigma^{\mathrm{D}}$ specific. The consensus sequence of $\sigma^{\mathrm{D}}$-specific promoters is currently being explored (Busche and Kalinowski, unpublished data).

In contrast to stress promoters, $\sigma^{\mathrm{A}}$ - and $\sigma^{\mathrm{B}}$-dependent promoters exhibited relatively high expression in all growth phases even without the overexpression of a sig gene. The cell levels of $\sigma^{\mathrm{A}}$ and $\sigma^{\mathrm{B}}$ are apparently high enough to drive expression from the tested promoters. Moreover, as was shown for the $\sigma^{\mathrm{B}}$-dependent promoters Ppqo (Šilar et al. 2016) and $\mathrm{P} f b a, \sigma^{\mathrm{A}}$ is able to partially substitute for missing $\sigma^{\mathrm{B}}$ in $\triangle \operatorname{sig} B$ strain. The ability of $\sigma^{\mathrm{A}}$ and $\sigma^{B}$ to recognize $\mathrm{P} f b a$ was confirmed by the in vitro transcription assays. This interchangeability of $\sigma^{\mathrm{A}}$ and $\sigma^{\mathrm{B}}$ was also shown for the typical housekeeping promoters Pper (Šilar et al. 2016) and P2sigA (Fig. 6b). This is not surprising since the amino acid sequences of $\sigma^{\mathrm{A}}$ and $\sigma^{\mathrm{B}}$ in protein regions 2.4 and 4.2 which recognize the -10 and -35 promoter motifs respectively are highly similar, and promoter consensus sequences of $\sigma^{\mathrm{A}}$ and $\sigma^{\mathrm{B}}$ could not be distinguished. These findings for C. glutamicum are analogous to those for E. coli $\sigma^{70}$ and $\sigma^{\mathrm{S}}$ (Typas et al. 2007).

Detailed knowledge of functions of $\sigma$ factors is a prerequisite for their engineering aimed at modulation of transcriptional regulatory network and, consequently, strain improvement for biotechnological purposes (Tripathi et al. 2014). Mutagenesis of $\sigma$ factors or other transcriptional regulators and screening the mutants for their ability to reprogram cellular metabolism and regulation to the desired phenotype is a basis of newly developed global transcriptional machinery engineering method (for a review, see Tyo et al. 2007; Lanza and Alper 2011; Liu and Jiang 2015). For the first time, this approach was used for improvement of ethanol tolerance and production in Saccharomyces cerevisiae by mutagenesis of transcription factor Spt15p (Alper et al. 2006). Random mutagenesis of E. coli primary $\sigma^{70}$ factor was found to result in global perturbations of the transcriptome and the mutants exhibiting ethanol tolerance, increased lycopene production and multiple tolerance phenotypes, respectively, were obtained (Alper and Stephanopoulos 2007). Screening the library of E. coli $\sigma^{70}$ factormutants under cyclohexane pressure resulted in obtaining the strains highly tolerant to this solvent (Zhang et al. 2015). E. coli strains accumulating hyaluronic acid effectively were obtained also by screening the $\sigma^{\mathrm{S}}$-mutants (Yu et al. 2008). 
The use of two alternative vectors (pEC-XT99A and pEKEx3) for overexpressing sig genes gave essentially the same results, which widens the choice for in vivo promoter analysis. A comparison of the results obtained with both in vivo and in vitro approaches proved to be useful for the unequivocal assignment of a sigma factor to a single promoter. Combining the advantages of in vivo and in vitro techniques can minimize the drawbacks of the techniques as stand-alone approaches and finally provide reliable sigma factor-promoter assignment.

\section{Additional file}

Additional file 1. Additional tables.

\begin{abstract}
Abbreviations
ECF: extracytoplasmic function; IPTG: isopropyl- $\beta$-D-1-thiogalactopyranoside; LC-MS/MS: liquid chromatography-tandem mass spectrometry; $\mathrm{OD}_{600}$ : optical density at $600 \mathrm{~nm}$; PBS: phosphate-buffered saline; RNAP: RNA polymerase; SD: standard deviation; SDS-PAGE: sodium dodecylsulfate polyacrylamide gel electrophoresis; TSS: transcriptional start site; WT: wild-type.
\end{abstract}

\section{Authors' contributions}

HD developed the two-plasmid system and carried out most of the in vivo experiments using the two-plasmid system, JH did the in vitro assays, TB analyzed some promoters and constructed several strains, LR constructed two-plasmid strains and checked their identity, AR did the analyses with the pEKEX3 vector, PH performed the mass spectrometry analysis, JN designed the PCR primers, analyzed DNA sequences and edited the manuscript, JK led the studies performed in Bielefeld and edited the manuscript and MP designed the study, coordinated the work and wrote the draft of the manuscript. All authors read and approved the final manuscript.

\section{Author details}

${ }^{1}$ Institute of Microbiology of the CAS, v. v. i., Vídeňská 1083, 14220 Praque 4, Czech Republic. ${ }^{2}$ Center for Biotechnology, Bielefeld University, 33594 Bielefeld, Germany.

\section{Acknowledgements}

We wish to thank Libor Krásný and Hana Šanderová (Institute of Microbiology, Prague) for many helpful discussions and technical advice and Pavel Branny (Institute of Microbiology, Prague) for critical reading of the manuscript. We also wish to thank H. Taniguchi and V. F. Wendisch (Bielefeld University) for kindly providing the constructs of pEKEx3 with sigma factor genes.

\section{Competing interests}

The authors declare that they have no competing interests.

\section{Availability of data and materials}

The data supporting the findings and conclusions of this study are included in the main manuscript and in the additional supporting materials.

\section{Funding}

This work was supported by Grant 17-06991S from the Czech Science Foundation and Institutional Research Project RVO61388971 from the Institute of Microbiology of the CAS.

\section{Publisher's Note}

Springer Nature remains neutral with regard to jurisdictional claims in published maps and institutional affiliations.

Received: 13 June 2017 Accepted: 16 June 2017

Published online: 24 June 2017

\section{References}

Alper H, Stephanopoulos G (2007) Global transcription machinery engineering: a new approach for improving cellular phenotype. Metab Eng 9:258-267. doi:10.1016/j.ymben.2006.12.002

Alper H, Moxley J, Nevoigt E, Fink GR, Stephanopoulos G (2006) Engineering yeast transcription machinery for improved ethanol tolerance and production. Science 314:1565-1568. doi:10.1126/science.1131969

Becker J, Wittmann C (2012) Bio-based production of chemicals, materials and fuels-Corynebacterium glutamicum as versatile cell factory. Curr Opin Biotechnol 23:631-640. doi:10.1016/j.copbio.2011.11.012

Busche T, Šilar R, Pičmanová M, Pátek M, Kalinowski J (2012) Transcriptional regulation of the operon encoding stress-responsive ECF sigma factor SigH and its anti-sigma factor RshA, and control of its regulatory network in Corynebacterium glutamicum. BMC Genom 13:445. doi:10.1186/1471-2164-13-445

Cho BK, Kim D, Knight EM, Zengler K, Palsson BO (2014) Genome-scale reconstruction of the sigma factor network in Escherichia coli: topology and functional states. BMC Biol 12:4. doi:10.1186/1741-7007-12-4

Ehira S, Shirai T, Teramoto H, Inui M, Yukawa H (2008) Group 2 sigma factor SigB of Corynebacterium glutamicum positively regulates glucose metabolism under conditions of oxygen deprivation. Appl Environ Microbiol 74:5146-5152. doi:10.1128/AEM.00944-08

Ehira S, Teramoto H, Inui M, Yukawa H (2009) Regulation of Corynebacterium glutamicum heat shock response by the extracytoplasmic-function sigma factor SigH and transcriptional regulators HspR and HrcA. J Bacteriol 191:2964-2972. doi:10.1128/JB.00112-09

Eikmanns BJ, Thum-Schmitz N, Eggeling L, Ludtke KU, Sahm H (1994) Nucleotide sequence, expression and transcriptional analysis of the Corynebacterium glutamicum gltA gene encoding citrate synthase. Microbiology 140:1817-1828

Halgasova N, Bukovska G, Timko J, Kormanec J (2001) Cloning and transcriptional characterization of two sigma factor genes, sigA and sigB, from Brevibacterium flavum. Curr Microbiol 43:249-254

Halgasova N, Bukovska G, Ugorcakova J, Timko J, Kormanec J (2002) The Brevibacterium flavum sigma factor SigB has a role in the environmental stress response. FEMS Microbiol Lett 216:77-84

Hanahan D (1985) Techniques for transformation of E. coli. In: Glover DM (ed) DNA cloning. A practical approach, vol 1. IRL, Oxford, pp 109-135

Hoffelder M, Raasch K, van Ooyen J, Eggeling L (2010) The E2 domain of OdhA of Corynebacterium glutamicum has succinyltransferase activity dependent on lipoyl residues of the acetyltransferase AceF. J Bacteriol 192:5203-5211. doi:10.1128/JB.00597-10

Holátko J, Šilar R, Rabatinová A, Šanderová H, Halada P, Nešvera J, Krásný L, Pátek M (2012) Construction of in vitro transcription system for Corynebacterium glutamicum and its use in the recognition of promoters of different classes. Appl Microbiol Biotechnol 96:521-529. doi:10.1007/ s00253-012-4336-1

Keilhauer C, Eggeling L, Sahm H (1993) Isoleucine synthesis in Corynebacterium glutamicum: molecular analysis of the ilvB-ilvN-ilvC operon. J Bacteriol 175:5595-5603

Kim MJ, Yim SS, Choi JW, Jeong KJ (2016) Development of a potential stationary-phase specific gene expression system by engineering of SigB-dependent cg3141 promoter in Corynebacterium glutamicum. Appl Microbiol Biotechnol 100:4473-4483. doi:10.1007/s00253-016-7297-y

Kirchner O, Tauch A (2003) Tools for genetic engineering in the amino acid-producing bacterium Corynebacterium glutamicum. J Biotechnol 104:287-299. doi:10.1016/S0168-1656(03)00148-2

Knoppová M, Phensaijai M, Veselý M, Zemanová M, Nešvera J, Pátek M (2007) Plasmid vectors for testing in vivo promoter activities in Corynebacterium glutamicum and Rhodococcus erythropolis. Curr Microbiol 55:234-239. doi:10.1007/s00284-007-0106-1

Lanza AM, Alper HS (2011) Global strain engineering by mutant transcription factors. Methods Mol Biol 765:253-274. doi:10.1007/978-1-61779-197-0_15

Larisch C, Nakunst D, Hüser AT, Tauch A, Kalinowski J (2007) The alternative sigma factor SigB of Corynebacterium glutamicum modulates global gene expression during transition from exponential growth to stationary phase. BMC Genom 8:4. doi:10.1186/1471-2164-8-4

Lisser S, Margalit H (1993) Compilation of E. coli mRNA promoter sequences. Nucleic Acids Res 21:1507-1516 
Liu W, Jiang R (2015) Combinatorial and high-throughput screening approaches for strain engineering. Appl Microbiol Biotechnol 99:20932104. doi:10.1007/s00253-015-6400-0

Nakunst D, Larisch C, Hüser AT, Tauch A, Pühler A, Kalinowski J (2007) The extracytoplasmic function-type sigma factor SigM of Corynebacterium glutamicum ATCC 13032 is involved in transcription of disulfide stressrelated genes. J Bacteriol 189:4696-4707. doi:10.1128/JB.00382.07

Nešvera J, Pátek M (2011) Tools for genetic manipulations in Corynebacterium glutamicum and their applications. Appl Microbiol Biotechnol 90:16411654. doi:10.1007/s00253-011-3272-9

Park SD, Youn JW, Kim YJ, Lee SM, Kim Y, Lee HS (2008) Corynebacterium glutamicum $\sigma^{\mathrm{E}}$ is involved in responses to cell surface stresses and its activity is controlled by the anti- $\sigma$ factor CseE. Microbiology 154:915-923. doi:10.1099/mic.0.2007/012690-0

Pátek M, Nešvera J (2011) Sigma factors and promoters in Corynebacterium glutamicum. J Biotechnol 154:101-113. doi:10.1016/j.jbiotec.2011.01.017

Pátek M, Holátko J, Busche T, Kalinowski J, Nešvera J (2013) Corynebacterium glutamicum promoters: a practical approach. Microb Biotechnol 6:103-117. doi:10.1111/1751-7915.12019

Pfeifer-Sancar K, Mentz A, Rückert C, Kalinowski J (2013) Comprehensive analysis of the Corynebacterium glutamicum transcriptome using an improved RNAseq technique. BMC Genom 14:888. doi:10.1186/1471-2164-14-888

Qiu Y, Nagarajan H, Embree M, Shieu W, Abate E, Juarez K, Cho BK, Elkins JG, Nevin KP, Barrett CL, Lovley DR, Palsson BO, Zengler K (2013) Characterizing the interplay between multiple levels of organization within bacterial sigma factor regulatory networks. Nat Commun 4:1755. doi:10.1038/ ncomms 2743

Rezuchova B, Kormanec J (2001) A two-plasmid system for identification of promoters recognized by RNA polymerase containing extracytoplasmic stress response $\sigma^{\mathrm{E}}$ in Escherichia coli. J Microbiol Methods 45:103-111

Rhodius VA, Segall-Shapiro TH, Sharon BD, Ghodasara A, Orlova E, Tabakh H, Burkhardt DH, Clancy K, Peterson TC, Gross CA, Voigt CA (2013) Design of orthogonal genetic switches based on a crosstalk map of os, anti-os, and promoters. Mol Syst Biol 9:702. doi:10.1038/msb.2013.58

Rodrigue S, Provvedi R, Jacques PE, Gaudreau L, Manganelli R (2006) The sigma factors of Mycobacterium tuberculosis. FEMS Microbiol Rev 30:926-941. doi:10.1111/j.1574-6976.2006.00040.x

Ross W, Thompson JF, Newlands JT, Gourse RL (1990) E. coli Fis protein activates ribosomal RNA transcription in vitro and in vivo. EMBO J 9:3733-3742

Sambrook J, Russel DV (2001) Molecular cloning. A laboratory manual, 3rd edn. Cold Spring Harbor Laboratory Press, Cold Spring Harbor

Schröder J, Tauch A (2010) Transcriptional regulation of gene expression in Corynebacterium glutamicum: the role of global, master and local regulators in the modular and hierarchical gene regulatory network. FEMS Microbiol Rev 34:685-737. doi:10.1111/j.1574-6976.2010.00228.x
Šilar R, Holátko J, Rucká L, Rapoport A, Dostálová H, Kadeřábková P, Nešvera J, Pátek M (2016) Use of in vitro transcription system for analysis of Corynebacterium glutamicum promoters recognized by two sigma factors. Curr Microbiol 73:401-408. doi:10.1007/s00284-016-1077-x

Taniguchi H, Wendisch VF (2015) Exploring the role of sigma factor gene expression on production by Corynebacterium glutamicum: sigma factor $\mathrm{H}$ and FMN as example. Front Microbiol 6:740. doi:10.3389/ fmicb.2015.00740

Toyoda K, Inui M (2016a) The extracytoplasmic function $\sigma$ factor $\sigma^{C}$ regulates expression of a branched quinol oxidation pathway in Corynebacterium glutamicum. Mol Microbiol 100:486-509. doi:10.1111/mmi.13330

Toyoda K, Inui M (2016b) Regulons of global transcription factors in Corynebacterium glutamicum. Appl Microbiol Biotechnol 100:45-60. doi:10.1007/ s00253-015-7074-3

Toyoda K, Teramoto H, Yukawa H, Inui M (2015) Expanding the regulatory network governed by the extracytoplasmic function sigma factor $\sigma^{\mathrm{H}}$ in Corynebacterium glutamicum. J Bacteriol 197:483-496. doi:10.1128/ JB.02248-14

Tripathi L, Zhang Y, Lin Z (2014) Bacterial sigma factors as targets for engineered or synthetic transcriptional control. Front Bioeng Biotechnol 2:33. doi:10.3389/fbioe.2014.00033

Tyo KE, Alper HS, Stephanopoulos GN (2007) Expanding the metabolic engineering toolbox: more options to engineer cells. Trends Biotechnol 25:132-137. doi:10.1016/j.tibtech.2007.01.003

Typas A, Becker G, Hengge R (2007) The molecular basis of selective promoter activation by the $\sigma^{5}$ subunit of RNA polymerase. Mol Microbiol 63:12961306. doi:10.1111/j.1365-2958.2007.05601.x

van der Rest ME, Lange C, Molenaar D (1999) A heat shock following electroporation induces highly efficient transformation of Corynebacterium glutamicum with xenogeneic plasmid DNA. Appl Microbiol Biotechnol 52:541-555

Yu H, Tyo K, Alper H, Klein-Marcuschamer D, Stephanopoulos G (2008) A highthroughput screen for hyaluronic acid accumulation in recombinant Escherichia coli transformed by libraries of engineered sigma factors. Biotechnol Bioeng 101:788-796. doi:10.1002/bit21947

Zemanová M, Kadeřábková P, Pátek M, Knoppová M, Šilar R, Nešvera J (2008) Chromosomally encoded small antisense RNA in Corynebacterium glutamicum. FEMS Microbiol Lett 279:195-201. doi:10.1111/j.1574-6968.2007.01024.X

Zhang F, Qian X, Si H, Xu G, Han R, Ni Y (2015) Significantly improved solvent tolerance of Escherichia coli by global transcription machinery engineering. Cell Fact 14:175. doi:10.1186/s12934-015-0368-4

\section{Submit your manuscript to a SpringerOpen ${ }^{\odot}$ journal and benefit from:}

- Convenient online submission

- Rigorous peer review

- Open access: articles freely available online

- High visibility within the field

- Retaining the copyright to your article

Submit your next manuscript at springeropen.com 